\title{
The Emerging Importance of Professional Liability Insurance Coverage for Pharmacists
}

\author{
Sumera Kazim ${ }^{1}$, Albert Wertheimer ${ }^{2}$ \\ ${ }^{1}$ Denver, USA; ${ }^{2}$ Temple University School of Pharmacy, Philadelphia, USA. \\ Email: sumera.kazin@temple.edu, albertw@temple.edu \\ Received November $29^{\text {th }}$, 2013; revised January $11^{\text {th }}$, 2014; accepted January $22^{\text {nd }}, 2014$ \\ Copyright (C) 2014 Sumera Kazim, Albert Wertheimer. This is an open access article distributed under the Creative Commons Attri- \\ bution License, which permits unrestricted use, distribution, and reproduction in any medium, provided the original work is properly \\ cited. In accordance of the Creative Commons Attribution License all Copyrights (C) 2014 are reserved for SCIRP and the owner of \\ the intellectual property Sumera Kazim, Albert Wertheimer. All Copyright (C) 2014 are guarded by law and by SCIRP as a guardian.
}

\section{ABSTRACT}

As the responsibilities for clinical pharmacists have increased in recent years, the pharmacy practitioner finds the need for professional liability insurance. This report describes the practice changes under way and describes the malpractice insurance options available to current pharmacy practitioners.

\section{KEYWORDS}

\section{Pharmacy Professional Liability; Pharmacist Malpractice Insurance}

\section{Introduction}

In the past few decades, the profession of pharmacy has become elevated to a doctoral profession with increased responsibility and patient care responsibilities. The field of pharmacy connects health science to the science of drugs. In each of the roles taken on by pharmacists, there is a significant opportunity for error to occur. When such medication errors occur, the pharmacist can be held liable, sometimes along with physicians. It has therefore become necessary for pharmacists to obtain professional liability insurance.

In the United States, community pharmacies are very popular and many exist even in grocery stores. The role of a pharmacist in a community pharmacy is to process prescriptions for patients, contact the physician if there is any drug-drug interaction, counsel patients on how to take their medication and what sort of side effects they may experience, and answer any question they have. A new trend in the past few years has been for pharmacists to administer vaccinations to adults, participate in medication therapy management (MTM) and also provide drug regimen problem solutions. Pharmacists are administering vaccinations to patients on a walk-in basis in addition to other responsibilities they hold. MTM came about through the Medicare Modernization Act of 2003 (MMA 2003). MTM has been another role that pharmac- ists have taken on in which they review each medication with the patient and make certain dosage, strength and formulation are correct along with counseling about the importance of adherence. Community pharmacists are also participating in solving drug regimen problems that may arise such as drug-drug interactions and incorrect dosages. In the community pharmacy setting, pharmacists are also involved in customer service and generating income for the pharmacy.

Hospital pharmacies are an important part of every healthcare system. In the hospital setting, pharmacists are responsible for checking prescriptions filled by technicians, looking for drug-drug interactions and making sure that the medications are delivered to the appropriate patients in a timely manner. Pharmacists check a variety of different types of medications and regimens including intravenous, intramuscular and subcutaneous dosage forms. In the hospital setting, pharmacists are challenged with more clinically significant patient medication regimens than they might see in a retail setting [1].

Clinical pharmacy practice is a more recent role that pharmacists have taken on. Clinical pharmacists usually have additional education obtained by a residency following pharmacy school graduation. They usually round with the medical team in the hospital and give direct input so as to optimize drug therapy regimens. 
Ambulatory pharmacy is also a new area that has emerged and gives a pharmacist authority to manage patients with chronic disease states such as hypertension, diabetes and asthma. In a clinic setting, pharmacists are able to change or add drugs to patients' regimens if they have a contractual agreement with patients' physicians.

Compounding pharmacy encompasses the production of unique medications that are not commercially available. In this field, pharmacists prepare mixtures of drugs with inactive ingredients in a dosage form best suited to treat the patient. This field requires meticulous technique and familiarity with pharmaceutical calculations in order to accurately incorporate the appropriate formulation.

Another important branch of pharmacy practice is consulting. Consulting pharmacists usually work in longterm care settings such as nursing homes. At these locations, pharmacists perform a sort of MTM in which they review patients' drug regimens and recommend modifications if necessary to the patients' physicians.

Mail order pharmacies have gained recognition in the past few years due to their ease and security that patients often feel. Mail order pharmacies send prescription drugs to the homes of patients after obtaining prescriptions from the doctor. Patients often prefer this method because it is easier and more convenient than making a trip to the pharmacy. This method is also preferred because it is discrete and may make patients feel more comfortable.

In all of the above-mentioned positions, errors can occur which could put the pharmacist in a precarious position. In the community setting, pharmacists are often overworked, especially in busy retail chain locations. Throughout their workday, they are juggling many tasks such as checking drugs, calling doctors, administering vaccines, ensuring there are not any drug-drug interactions, counseling patients when asked and supervising the technicians. With busy retail settings filling around 500 prescriptions daily, many opportunities for error are present. For example, if a patient gets a medication dispensed at various chain pharmacies that are not linked in the computer system and the pharmacist does not ask them if they are taking any other medications and a severe drug interaction occurs, the pharmacist could be held liable for not taking the time to ask the patient and obtaining a full patient medication profile.

The case of Hundley ex rel. Hundley v. Rite Aid of South Carolina, Inc. is an example of incorrect dispensing of a medication that ended in brain damage to a minor. The family was awarded $\$ 11$ million in punitive damages against the pharmacy. The character and past performance of the pharmacist were brought to light indicating that he was "older, had a history of not filling prescriptions properly and acted indifferently to the life, health and safety of others". Another example of retail pharmacy negligence is Harco Drugs, Inc v. Holloway in which a breast cancer patient sued the pharmacy for misfilling the patient's cancer medication with a heart medication and awarded the patient $\$ 100,000$ in compensatory damages and $\$ 150,000$ in punitive damages. Throughout previous law literature, there are many examples of medications being mis-filled or inappropriately compounded by pharmacists. Now that pharmacists have taken on additional roles, there are even more avenues for potential error that have arisen [2].

In most major hospitals, pharmacists are part of a code team that resuscitates patients who are in shock. The pharmacists are responsible for quickly drawing up the proper drugs with which to medicate these patients. With this responsibility, if a pharmacist were to make a mistake, they would be held liable.

Also in a hospital, you would find clinical pharmacists who round with the medical team. In this position, clinical pharmacists are making recommendations to doctors about patients' drugs. A wrong recommendation that is accepted would leave the pharmacist accountable for the damage. The risk of error and liability has increased with increasing education and responsibility that the pharmacist has taken on. Schroeder v. Lester E. Cox Medical Center Inc. is an example of a hospital pharmacy compounding error. It was a wrongful death action filed against a pharmacy that supplied improperly compounded cardioplegic solution used during a patient's open-heart surgery that resulted in the patient's death. Damages totaled about $\$ 500,000$ for aggravating circumstances [3].

Pharmacists in the ambulatory setting have immense responsibility especially if they have a clinic that manages patients with chronic diseases and they are able to prescribe and adjust drug regimens under formal agreement with the primary care physician. If a pharmacist was to prescribe an incorrect drug or change the dosing regimen of a medication that led to a severe adverse outcome, they would probably be accused of negligence. The Supreme Court of Alabama ruled in Springhill Hospitals $v$. Larrimore that a pharmacist functioning in a dispensing role is not liable to a patient for harm caused by a physician's order when the pharmacist has provided consultation to the physician regarding the order. However, the left court opens the possibility that a pharmacist who provides consultation in a clinical setting, having voluntarily undertaken to provide clinical care, and with specific knowledge of a patient's medical history, may be liable for harm to the patient caused by a physician's order. This case shows that contemporary practice of pharmacy and additional roles such as providing MTM create more error opportunities [4].

Compounding prescription drugs has been part of a pharmacist's role since the profession began. In recent times, many pharmacies have chosen to obtain their compounded medications from specialized pharmacies, 
thereby freeing up time to fill other medications. Many long-term care pharmacy providers and hospital pharmacies utilize specialized compounding pharmacies. When compounding a prescription, a pharmacist needs to be able to accurately perform the proper calculations, measure the precise amount of product and mix it together in the best way possible. This position requires diligence and scrupulous technique. If a pharmacist was to perform the wrong calculations and combine the wrong amount of active ingredient, serious medical complications could result.

The threat of liability is present in mail order pharmacies as well. In mail order pharmacies, pharmacists are mostly checking prescriptions on a conveyer belt that have been filled by technicians. The offer to counsel a patient must be made in writing or via telephone call, but many times mail order pharmacies merely send the offer on a piece of paper along with the medication. Patients may just toss the paper aside, thinking it is part of the packaging, and in turn not become fully informed of the adverse effects and what to expect from the medication that they are consuming [4].

It is evident that the role of a pharmacist has become much diversified and encompasses significant responsibility. The scenarios just described are only some of the ways that pharmacists have increased their risk for medication errors and litigation. Well documented studies have shown that the majority of errors occur in physician ordering, administration by a nurse, transcription of the prescription at the pharmacy, and dispensing of the drug by the pharmacy. Some ways to decrease potential for error in some areas of pharmacy practice would be to instill a system of multiple check points before dispensing a medication, adequate documentation, acquiring full patient medication profiles, periodically retraining employees on ways to prevent errors, and taking time to counsel patients. These are just some of the many ways that pharmacists can decrease the occurrence of errors [5].

\section{Moving into the Future: The Increasing Need for Malpractice Insurance}

With the above-mentioned roles of a pharmacist in to- day's healthcare system, it is advisable that pharmacists obtain malpractice insurance. In the past, malpractice insurance was mostly associated with physicians and surgeons, while pharmacists were not held liable for negligence unless they made a dispensing error. However, now pharmacists are being held responsible for the increased duty associated with the increased education and training that comes with a doctoral degree. These errors are looked at as "intellectual errors." Courts are beginning to entertain new theories of malpractice liability against pharmacists. The Omnibus Reconciliation Act of 1990 (OBRA 90') was an important act that clearly defined the increasing role of the pharmacist and with those additional duties arose additional areas for patient negligence. Through this act, the role of a pharmacist became more important and entailed prospective drug review, offer to counsel and patient education. This meant that pharmacists were also being held to a higher standard than had previously been expected of the profession [6].

The medical profession has always been known to have significant premiums for malpractice coverage because there is considerable room for error. An example of yearly premium rates for medical doctors is shown in Table 1 [6].

The rates were shown to vary by geographic location, type of community, practice size, years in practice, number of patient visits per week, number of hours worked and also surprisingly by the physician's age. Higher premiums were found in the eastern United States. [7] Urban and suburban communities tended to have higher rates, and practices with greater numbers of physicians had higher rates. Physicians who had a greater amount of patient visits per week and who worked more hours per week had larger premiums as well. Surprisingly physicians who were middle aged had greater premiums than those less than 35 years old or greater than 55 years old $[7,8]$.

More and more insurance companies are offering malpractice insurance for pharmacists. In the Pennsylvania/ New Jersey region there are many options to choose from as described in Table 2.

The rates for pharmacist professional liability insurance are considerably lower than those for other health

Table 1. Annual malpractice rates for medical doctors.

\begin{tabular}{ccc}
\hline & 2009 & 2010 \\
\hline Family Physician/General Practitioner & $\$ 12,600$ & $\$ 12,100$ \\
Internists & $\$ 14,500$ & $\$ 13,100$ \\
Pediatricians & $\$ 11,500$ & $\$ 11,800$ \\
Ob/GYN & $\$ 55,000$ & $\$ 46,000$ \\
\hline
\end{tabular}


Table 2. Premium rates for pharmacists.

\begin{tabular}{|c|c|c|c|}
\hline Insurance Company & $\begin{array}{l}\text { Pharmacist } \\
\text { coverage per year }\end{array}$ & $\begin{array}{c}\text { Consulting } \\
\text { Pharmacist-coverage per year }\end{array}$ & Comments \\
\hline $\begin{array}{l}\text { HPSO (Health Providers } \\
\text { Service Organization) }\end{array}$ & $\$ 144$ & $\$ 375$ & $\begin{array}{l}\text { Also provide coverage for a pharmacy: Pharmacy } \\
\text { insurance depends on building structure, what is } \\
\text { contained and territory (i.e. crime, location), average } \\
\text { cost to insure a pharmacy in Philadelphia, PA that } \\
\text { is privately owned/independent is } \$ 7964 / \text { year }\end{array}$ \\
\hline Jospeh A. Britton Agency & $\$ 250$ & $\$ 250$ & $\begin{array}{l}\text { It costs } \$ 250 / \mathrm{yr} \text { for } \mathrm{NJ} \text { pharmacists but prices for PA } \\
\text { can vary and are divided up by territories }\end{array}$ \\
\hline $\begin{array}{l}\text { Pharmacists Mutual } \\
\text { Insurance }\end{array}$ & $\$ 144$ & $\$ 144$ & $\begin{array}{l}\text { There is a } 50 \% \text { discount for first year PA pharmacists } \\
\text { then it goes up to } \$ 144 / \text { yr. This company also covers } \\
\text { pharmacies based upon infrastructure and average } \\
\text { sales/store. }\end{array}$ \\
\hline $\begin{array}{l}\text { Probability Professional } \\
\text { Liability Insurance }\end{array}$ & $\$ 111$ & $\$ 311$ & $\begin{array}{l}\text { For a first year pharmacist it costs } \$ 56 / \mathrm{yr} \text { and } \$ 156 / \mathrm{yr} \\
\text { (for consulting pharmacists). Members of a professional } \\
\text { organization may receive } 10 \% \text { discount }\end{array}$ \\
\hline $\begin{array}{l}\text { Lockton Affinity- } \\
\text { AphO Insurance }\end{array}$ & $\$ 340$ & $\$ 340$ & $\begin{array}{l}\text { Rate is based upon how many hours worked/week. } \\
\text { If pharmacist is self-employed then rate is } \$ 646 / y r\end{array}$ \\
\hline
\end{tabular}

"Limits of liability: \$1,000,000 to \$3,000,000; "Information regarding rate of claims involving pharmacists were not available from the insurance providers.

professionals, and should therefore be perceived as a worthwhile investment.

\section{REFERENCES}

[1] D. Brushwood, "Hospital Liability for Accuracy of Pharmacist Consultations," American Journal of Health-System Pharmacy, Vol. 66, No. 7, 2009, pp 680-683. http://dx.doi.org/10.2146/ajhp080626

[2] M. A. J. D. Shields, "Exemplary or Punitive Damages for Pharmacist's Wrongful Conduct in Preparing or Dispensing Medical Prescription-Cases Not under Consumer Product Safety Act,” LexisNexis, 2012.

[3] L. P. Wateska, "Some Legal Implications Arising from Changes in the Practice of Pharmacy," Journal of Legal Medicine, Vol. 26, 2007, 34-37.
[4] F. R. Vogenberg, "The Medication-Use Process and the Importance of Mastering Fundamentals,” Healthcare and Law, Vol. 36, No. 10, 2011, pp. 651-652.

[5] A. Gifford, "PAs in the ED: Do Physicians Think They Increase the Malpractice Risk?” JAAPA, Vol. 24, No. 6, 2011, pp. 34, 36-38.

[6] B. T. Hertz, "Malpractice Rates Plateauing. The Only Thing to Fear May Be Fear Itself," Medical Economics, Vol. 88, No. 22, 2011, pp. 24-25.

[7] American Nurses Association, "What Every Nurse Should Know about Professional Liability Insurance," Tar Heel Nurse, Vol. 67, No. 4, 2005, p. 18.

[8] J. Vivian, "Pharmacy Practice: Crisis or Crucible?” American Pharmacy, Vol. 34, No. 4, 1994, pp. 25-30. 